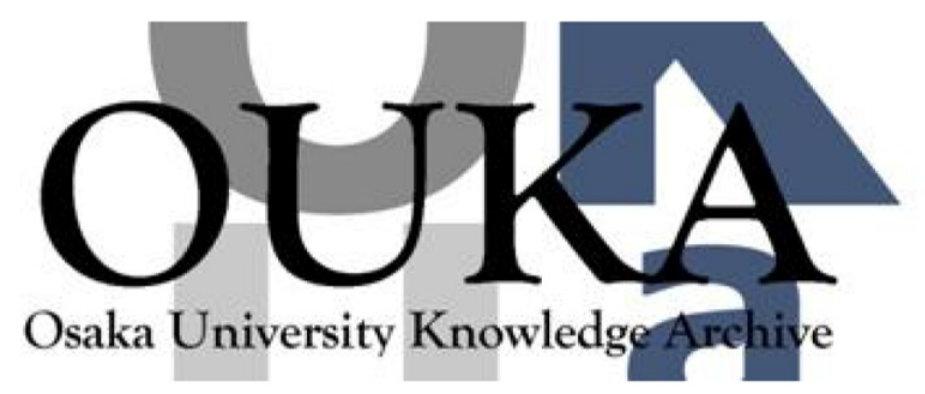

\begin{tabular}{|c|l|}
\hline Title & $\begin{array}{l}\text { Nationwide public-access defibrillation in } \\
\text { Japan }\end{array}$ \\
\hline Author(s) & $\begin{array}{l}\text { Kitamura, Tetsuhisa; Iwami, Taku; Kawamura, } \\
\text { Takashi et al. }\end{array}$ \\
\hline Citation & $\begin{array}{l}\text { New England Journal of Medicine. 362(11) p. 994- } \\
\text { p. 1004 }\end{array}$ \\
\hline Issue Date & $2010-03-18$ \\
\hline oaire:version & VoR \\
\hline URL & https://hdl. handle. net/11094/78419 \\
\hline rights & $\begin{array}{l}\text { ○ 2010 Massachusetts Medical Society. Reprinted } \\
\text { with permission. }\end{array}$ \\
\hline Note & \\
\hline
\end{tabular}

Osaka University Knowledge Archive : OUKA

https://ir. Library. osaka-u. ac. jp/

Osaka University 


\title{
Nationwide Public-Access Defibrillation in Japan
}

\author{
Tetsuhisa Kitamura, M.D., Taku Iwami, M.D., Takashi Kawamura, M.D., \\ Ken Nagao, M.D., Hideharu Tanaka, M.D., and Atsushi Hiraide, M.D., \\ for the Implementation Working Group for the All-Japan Utstein Registry \\ of the Fire and Disaster Management Agency**
}

\section{ABSTRACT}

\begin{abstract}
From Kyoto University Health Service (T. Kitamura, T.I., T. Kawamura) and the Center for Medical Education, Kyoto University Graduate School of Medicine (A.H.) - both in Kyoto, Japan; and the Department of Cardiology, Cardiopulmonary Resuscitation and Emergency Cardiovascular Care, Surugadai Nihon University Hospital (K.N.), and the Graduate School of Sport System, Kokushikan University (H.T.) - both in Tokyo. Address reprint requests to Dr. Iwami at Kyoto University Health Service, Yoshida-Honmachi, Sakyo-ku, Kyoto 606-8501, Japan, or at iwamit@e-mail.jp.

*The investigators and coordinators participating in the Implementation Working Group for the All-Japan Utstein Registry of the Fire and Disaster Management Agency of Japan are listed in the Appendix.
\end{abstract}

N Engl J Med 2010;362:994-1004.

Copyright (c) 2010 Massachusetts Medical Society.

\section{BACKGROUND}

It is unclear whether dissemination of automated external defibrillators (AEDs) in public places can improve the rate of survival among patients who have had an out-ofhospital cardiac arrest.

\section{METHODS}

From January 1, 2005, through December 31, 2007, we conducted a prospective, population-based, observational study involving consecutive patients across Japan who had an out-of-hospital cardiac arrest and in whom resuscitation was attempted by emergency responders. We evaluated the effect of nationwide dissemination of public-access AEDs on the rate of survival after an out-of-hospital cardiac arrest. The primary outcome measure was the 1-month rate of survival with minimal neurologic impairment. A multivariate logistic-regression analysis was performed to assess factors associated with a good neurologic outcome.

RESULTS

A total of 312,319 adults who had an out-of-hospital cardiac arrest were included in the study; 12,631 of these patients had ventricular fibrillation and had an arrest that was of cardiac origin and that was witnessed by bystanders. In 462 of these patients (3.7\%), shocks were administered by laypersons with the use of public-access AEDs, and the proportion increased, from $1.2 \%$ to $6.2 \%$, as the number of public-access AEDs increased $(\mathrm{P}<0.001$ for trend). Among all patients who had a bystander-witnessed arrest of cardiac origin and who had ventricular fibrillation, $14.4 \%$ were alive at 1 month with minimal neurologic impairment; among patients who received shocks from public-access AEDs, 31.6\% were alive at 1 month with minimal neurologic impairment. Early defibrillation, regardless of the type of provider (bystander or emergency-medical-services personnel), was associated with a good neurologic outcome after a cardiac arrest with ventricular fibrillation (adjusted odds ratio per 1-minute increase in the time to administration of shock, $0.91 ; 95 \%$ confidence interval, 0.89 to $0.92 ; \mathrm{P}<0.001$ ). The mean time to shock was reduced from 3.7 to 2.2 minutes, and the annual number of patients per 10 million population who survived with minimal neurologic impairment increased from 2.4 to 8.9 as the number of public-access AEDs increased from fewer than 1 per square kilometer of inhabited area to 4 or more.

\section{CONCLUSIONS}

Nationwide dissemination of public-access AEDs in Japan resulted in earlier administration of shocks by laypersons and in an increase in the 1-month rate of survival with minimal neurologic impairment after an out-of-hospital cardiac arrest. 
S:

UDDEN DEATH FROM CARDIAC ARREST IS a major public health problem in the industrialized world. ${ }^{1}$ The rate of survival after an out-of-hospital cardiac arrest has been increasing as improvements are made in connecting the links in the "chain of survival," but it is still low..$^{1-3}$ Although early defibrillation plays a key role in the chain of survival, 1,4 it is difficult to reduce the time from a patient's collapse to defibrillation by emergency medical service personnel.

One way to improve the rate of survival after an out-of-hospital cardiac arrest is to have laypersons administer defibrillation to the patient immediately, with the use of an automated external defibrillator (AED). Many studies, including a large, randomized trial, ${ }^{5-10}$ have shown that a public-access-defibrillation program improves the rate of survival among patients with an outof-hospital cardiac arrest, and as a result of these findings, public-access-defibrillation programs have been introduced in many areas. However, these studies were conducted in limited geographic areas or situations, ${ }^{1,5-12}$ and whether the nationwide dissemination of public-access AEDs would actually increase the rate of survival among people who have had an out-of-hospital cardiac arrest remains to be determined.

Since July 2004, it has been legal for any citizen in Japan to use an AED, and public-access AEDs have become increasingly available. ${ }^{13}$ In January 2005, the Fire and Disaster Management Agency (FDMA) of Japan launched a prospective, nationwide, population-based, cohort study involving persons who had an out-of-hospital cardiac arrest. The purpose of the study is to evaluate the effect of the nationwide dissemination of public-access AEDs on the rate of survival among patients who have had an out-of-hospital cardiac arrest of cardiac origin.

\section{METHODS}

\section{STUDY DESIGN}

The All-Japan Utstein Registry of the FDMA is a prospective, nationwide, population-based registry of out-of-hospital cardiac arrests that is based on the standardized Utstein style. ${ }^{14,15}$ We enrolled in this observational study all patients 18 years of age or older who, between January 1, 2005 , and December 31, 2007, had an out-of-hospital cardiac arrest of cardiac origin before the arrival of emergency medical services (EMS) personnel, were treated by EMS personnel, and were then transported to medical institutions. The ethics committee at Kyoto University Graduate School of Medicine approved the study. The requirement of written informed consent was waived.

Cardiac arrest was defined as the cessation of cardiac mechanical activity, as confirmed by the absence of signs of circulation. ${ }^{14,15}$ The arrest was presumed to be of cardiac origin unless it was caused by cerebrovascular disease; respiratory disease; malignant tumors; external factors, including trauma, hanging, drowning, drug overdose, and asphyxia; or any other noncardiac factor. The cardiac or noncardiac origin was determined clinically by the physician in charge, in collaboration with the EMS personnel, and was confirmed by a staff member at the FDMA.

\section{EMS SYSTEM IN JAPAN}

Japan has an area of approximately $378,000 \mathrm{~km}^{2}$ and an inhabited area of $121,000 \mathrm{~km}^{2}$ (defined in Japan as areas in which people can live, excluding forests, fields, marshes, and lakes), ${ }^{16}$ and its population was approximately 127 million in 2005. ${ }^{17}$ There were 807 fire stations with dispatch centers in 2007; EMS at these fire stations is provided by municipal governments. In most cases, an ambulance has a crew of three emergency providers, including at least one emergency lifesaving technician, a person who has undergone extensive training in the provision of emergency care before a patient's arrival at the hospital. Emergency lifesaving technicians are allowed to insert an intravenous line and an adjunct airway and to use semiautomated external defibrillators to treat patients who are having an out-of-hospital cardiac arrest. Since July 2004, specially trained emergency lifesaving technicians have been permitted to insert tracheal tubes, and since April 2006, they have been permitted to administer intravenous epinephrine. All EMS providers perform cardiopulmonary resuscitation (CPR) according to the Japanese CPR guidelines, which until September 2006 were based on the 2000 American Heart Association (AHA) guidelines and since October 2006 have been based on the 2005 AHA guidelines. ${ }^{18}$ EMS providers are not permitted to terminate resuscitation in the field. Therefore, most patients with an out-of-hospital cardiac arrest who are treated by EMS personnel are transported to hospitals. Training in conventional CPR, which includes chest compressions and rescue breathing, as outlined in the Japanese CPR guidelines, has been offered to approximately 1.4 mil- 


\begin{tabular}{|c|c|c|c|c|}
\hline Variable & Total & 2005 & 2006 & 2007 \\
\hline \multicolumn{5}{|l|}{ Public-access AEDs (no.) } \\
\hline Total & 88,265 & 9906 & 43,212 & 88,265 \\
\hline Per square kilometer of inhabited area & 0.97 & 0.11 & 0.48 & 0.97 \\
\hline Per 100,000 population & 69.0 & 7.8 & 33.8 & 69.0 \\
\hline \multicolumn{5}{|l|}{$\begin{array}{c}\text { Out-of-hospital cardiac arrests per } \\
100,000 \text { population }(\%) \dagger\end{array}$} \\
\hline Total & 54.1 & 52.8 & 54.2 & 55.3 \\
\hline Of presumed cardiac origin & 28.0 & 27.8 & 27.9 & 28.4 \\
\hline $\begin{array}{l}\text { Of presumed cardiac origin and } \\
\text { witnessed by bystanders }\end{array}$ & 9.6 & 9.2 & 9.5 & 9.8 \\
\hline $\begin{array}{l}\text { Of presumed cardiac origin, with } \\
\text { ventricular fibrillation, and } \\
\text { witnessed by bystanders }\end{array}$ & 2.6 & 2.5 & 2.7 & 2.8 \\
\hline
\end{tabular}

* Data are from Marukawa. ${ }^{13}$

$\dagger$ The incidence of out-of-hospital cardiac arrests was adjusted for age.

lion Japanese citizens per year, mainly by members of local fire departments. ${ }^{19}$

\section{DISSEMINATION OF AEDS IN JAPAN}

Since July 2004, it has been legal for any citizen in Japan to use an AED. Placement of AEDs in public areas, including schools, medical and nursing facilities, work places, sports and cultural facilities, and transportation facilities, depends on both public and private initiatives. ${ }^{20,21}$ The cumulative number of public-access AEDs, excluding those in medical facilities and EMS institutions, as estimated from sales of AEDs, increased from 9906 to 88,265 during the 3-year study period (Table 1). ${ }^{13}$

\section{DATA COLLECTION AND QUALITY CONTROL}

Data were collected prospectively with the use of a data form that was based on the Utstein-style guidelines for reporting out-of-hospital cardiac arrests ${ }^{14,15}$; the data that were collected included the sex and age of the patient, the initial cardiac rhythm, and the time course of resuscitation, as well as information on whether the arrest was witnessed by a bystander, whether a bystander initiated CPR, whether the patient was intubated, whether epinephrine was administered, and whether spontaneous circulation was restored before the patient's arrival at the hospital. In addition, information was collected on survival and neurologic status 1 month after the event. The times of the receipt of an emergency call by the EMS, the arrival of a vehicle at the scene, the initial contact with the patient, the initiation of CPR, defibrillation by EMS personnel, and arrival at the hospital were recorded according to the times on the clock used by the EMS system that responded to the call. An AED analyzes a patient's rhythm automatically and delivers a shock only when it detects ventricular fibrillation. Therefore, when laypersons delivered shocks with the use of a public-access AED, the patient's first recorded rhythm was regarded as ventricular fibrillation, which included ventricular tachycardia in the absence of a pulse. In cases in which bystanders initiated CPR, chest compression alone and conventional CPR with rescue breathing were recorded as "CPR by bystander." The times of collapse, administration of the first shock from a publicaccess AED, and initiation of CPR by a bystander were determined through an interview that EMS personnel conducted with the bystander before the EMS personnel left the scene. If the time of administration of the first shock from the publicaccess AED was not ascertained, the interval from the patient's collapse to administration of a shock from the AED was replaced with the interval from the patient's collapse to the time CPR was administered by the bystander. The time of the initiation of CPR was defined as the time CPR was initiated by bystanders or by EMS personnel, whichever was earlier. Similarly, the time of the administration of the first shock was defined as the time of the administration of the shock by laypersons or by EMS personnel, whichever was earlier.

All patients who survived the cardiac arrest were followed for up to 1 month after the event by the EMS providers in charge. Neurologic outcome was determined by means of a follow-up interview 1 month after successful resuscitation, with the use of the Cerebral Performance Category (CPC) scale, on which category 1 represents good cerebral performance; category 2 , moderate cerebral disability; category 3 , severe cerebral disability; category 4 , coma or vegetative state; and category 5 , death. ${ }^{14,15}$

The data form was completed by the EMS personnel in cooperation with the physicians in charge of the patients and was transferred to their fire stations; the data were then integrated into the registry system on the FDMA database 
server. The data were checked for consistency by the computer system and were confirmed by the study investigators. If the data form was incomplete, the FDMA returned it to the fire station, and the form was completed.

\section{END POINTS}

The primary end point was survival at 1 month with minimal neurologic impairment, which was defined as a CPC category of 1 or $2 .^{14,15}$ Secondary end points were the return of spontaneous circulation before arrival at the hospital and survival at 1 month.

\section{STATISTICAL ANALYSIS}

Data on cardiac arrests that were of cardiac origin, involved patients who were in ventricular fibrillation, and were witnessed by a bystander were included in the analyses. The age-adjusted annual incidence of out-of-hospital cardiac arrests was calculated with the use of 2005 census data and data from a 1985 Japanese population model. ${ }^{17,22}$ Trends in categorical and continuous variables were analyzed with the use of univariate regression models and linear tests. A multivariate analysis was used to assess the factors associated with a good neurologic outcome, and odds ratios and their 95\% confidence intervals were calculated. Potential confounding factors that were adjusted for in the multivariate analysis included the sex and age of the patient, the relation of the bystander to the patient (family member or other), the type of CPR initiated by a bystander (compression-only or conventional CPR), the use or nonuse of a public-access AED to administer a first shock, the time from the patient's collapse to the initiation of CPR, and the time from the patient's collapse to the first shock. The interaction between the provider of the shock (bystander using a public-access AED or EMS personnel) and the time to the first shock was also incorporated in the multivariate analysis. The mean time from collapse to shock, the annual incidence of the administration of a shock with the use of a public-access AED, and the subsequent rate of survival with minimal neurologic impairment per 10 million daytime population were compared among prefectures according to the number of public-access AEDs per square kilometer of inhabited area $(<1$, 1 to $<4$, or 4 or more). All statistical analyses were performed with the use of the SPSS statistical package, version 16.0J (SPSS). All tests were two- tailed, and $\mathrm{P}$ values of less than 0.05 were considered to indicate statistical significance.

RESULTS

CARDIAC ARRESTS AND AVAILABILITY OF PUBLICACCESS AEDS

During the 3 years of the study, 312,319 out-ofhospital cardiac arrests in adults were documented (Fig. 1), of which 168,827 were presumed to be of cardiac origin; 55,271 of these were witnessed by bystanders. A total of 12,631 adults with a cardiac arrest of cardiac origin witnessed by a bystander had an initial ventricular fibrillation. Of these, 462 received a first shock from a publicaccess AED before the arrival of EMS personnel, 11,697 received a first shock from EMS personnel, and 472 received no shocks.

Over the course of the 3-year study period, the number of public-access AEDs increased from 0.11 to 0.97 per square kilometer of inhabited area (Table 1). The age-adjusted annual incidence of out-of-hospital cardiac arrests among adults during the study period was 54.1 per 100,000 person-years, and the incidence of out-of-hospital cardiac arrests of cardiac origin was 28.0 per 100,000 person-years. Of these arrests, 9.6 per 100,000 person-years were witnessed by a bystander and 2.6 per 100,000 person-years also involved patients who were in ventricular fibrillation. Incidences gradually increased year by year.

SURVIVAL WITH MINIMAL NEUROLOGIC IMPAIRMENT Among the people who received a first shock from a public-access AED, the rate of survival with minimal neurologic impairment at 1 month was $84.5 \%$ for patients in whom spontaneous circulation was restored before the arrival of EMS personnel (71 of 84 patients), as compared with $22.9 \%$ for those who continued to have ventricular fibrillation (32 of 140) and 18.1\% for those who did not have ventricular fibrillation but had pulseless electrical activity or asystole at the time that EMS personnel administered CPR (43 of 238). Data on neurologic outcome 1 month after the event were not available for 55 of the 12,631 patients who had bystander-witnessed arrests and ventricular fibrillation.

\section{TEM PORAL TRENDS}

Table 2 shows temporal trends in the characteristics of the patients and in the outcomes of 


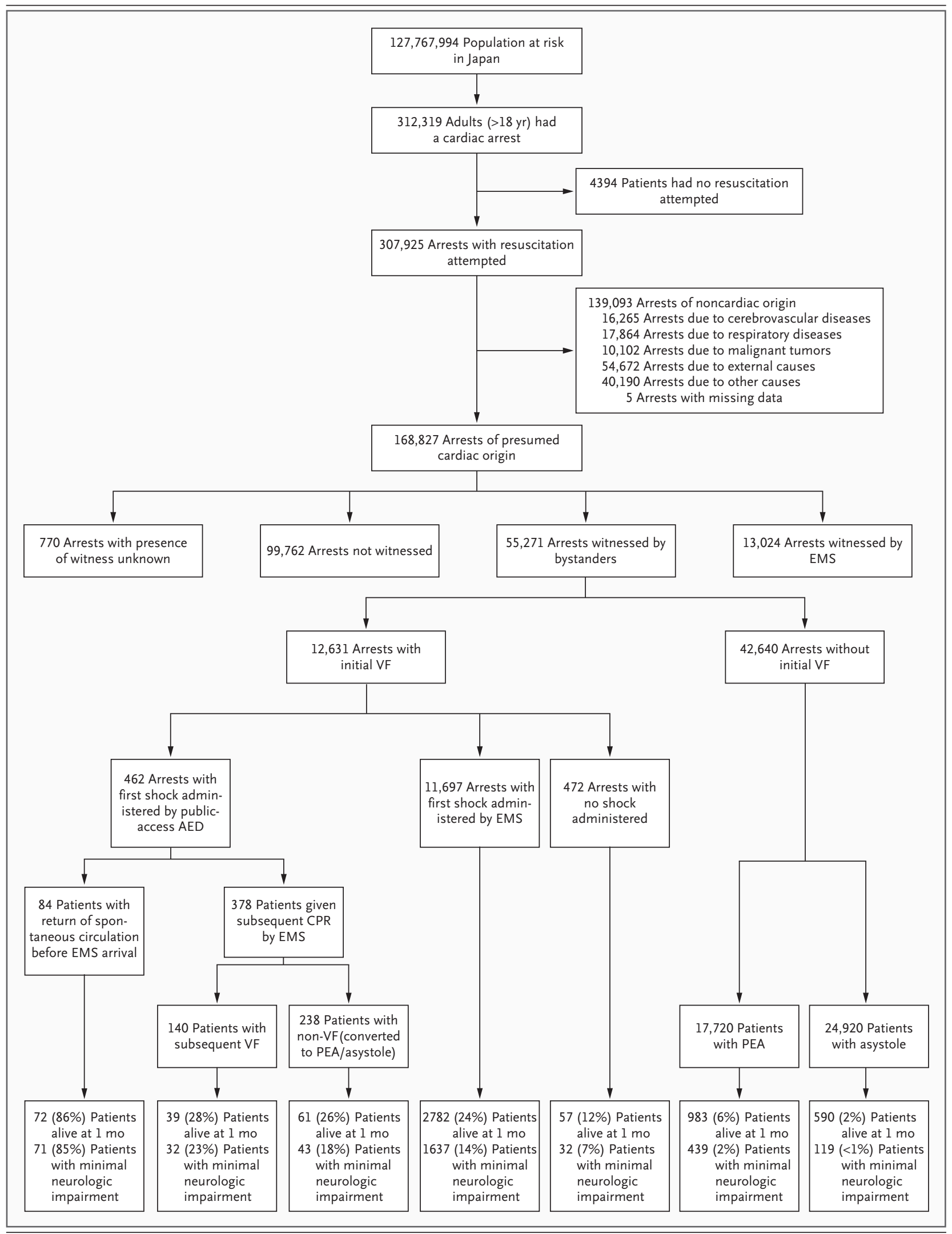

The New England Journal of Medicine 
Figure 1 (facing page). Study Population and Outcomes. AED denotes automated external defibrillator, CPR cardiopulmonary resuscitation, EMS emergency medical service, PEA pulseless electrical activity, and VF ventricular fibrillation.

bystander-witnessed arrests among patients who had ventricular fibrillation and arrests for which public-access AEDs were used to administer the first shock. Among bystander-witnessed arrests in patients who had ventricular fibrillation, no significant temporal trend was found in either the mean age of the patients or the ratio of male to female patients. Over the course of the 3 years, the prevalence of bystander-initiated CPR increased from $43.3 \%$ to $53.6 \%$ ( $\mathrm{P}<0.001$ ). Compression-only CPR accounted for more than $50 \%$ of cardiac arrests involving bystander-initiated $\mathrm{CPR}$. The time from the patient's collapse to the initiation of CPR decreased from 6.5 minutes to 5.7 minutes $(\mathrm{P}<0.001)$, whereas the time to ad-

Table 2. Temporal Trends in Characteristics and Outcomes of Bystander-Witnessed Arrests among Patients with Ventricular Fibrillation and in the Use of a Public-Access Automated External Defibrillator (AED) to Administer a First Shock.**

\begin{tabular}{|c|c|c|c|c|c|}
\hline Variable & Total & 2005 & 2006 & 2007 & $\begin{array}{l}\text { P Value for } \\
\text { Trend }\end{array}$ \\
\hline \multicolumn{6}{|l|}{ Bystander-witnessed arrests with ventricular fibrillation } \\
\hline No. of events & 12,631 & 3841 & 4388 & 4402 & \\
\hline Patient's age $-y r$ & $64.4 \pm 15.1$ & $64.4 \pm 14.8$ & $64.6 \pm 15.0$ & $64.1 \pm 15.4$ & 0.33 \\
\hline Male sex - no. of patients (\%) & $10,055(79.6)$ & $3066(79.8)$ & $3488(79.5)$ & $3501(79.5)$ & 0.75 \\
\hline Relationship of bystander to patient — no. (\%) & & & & & $<0.001$ \\
\hline Family member & $7376(58.4)$ & $2324(60.5)$ & $2577(58.7)$ & $2475(56.2)$ & \\
\hline Other & $5255(41.6)$ & $1517(39.5)$ & $1811(41.3)$ & $1927(43.8)$ & \\
\hline CPR initiated by bystander - no. of events $(\%) \uparrow$ & $6127(48.5)$ & $1662(43.3)$ & $2106(48.0)$ & $2359(53.6)$ & $<0.001$ \\
\hline Chest compression only & $3148(24.9)$ & $744(19.4)$ & $1037(23.6)$ & $1367(31.1)$ & \\
\hline Conventional CPR & $2979(23.6)$ & $918(23.9)$ & $1069(24.4)$ & $992(22.5)$ & \\
\hline Time from collapse to initiation of CPR - min & $6.0 \pm 5.8$ & $6.5 \pm 6.0$ & $6.0 \pm 5.6$ & $5.7 \pm 5.8$ & $<0.001$ \\
\hline Time from collapse to first shock - min $\mathbb{3}$ & $11.6 \pm 6.3$ & $12.0 \pm 6.2$ & $11.4 \pm 6.2$ & $11.6 \pm 6.5$ & 0.36 \\
\hline $\begin{array}{l}\text { Restoration of spontaneous circulation before arrival at hospital } \\
\quad \text { - no. of patients (\%) }\end{array}$ & $3118(24.7)$ & $821(21.4)$ & 1049 (23.9) & $1248(28.4)$ & $<0.001$ \\
\hline Survival at 1 mo - no. of patients (\%) & $3011(23.8)$ & $745(19.4)$ & $1019(23.2)$ & $1247(28.3)$ & $<0.001$ \\
\hline $\begin{array}{l}\text { Survival at } 1 \text { mo with minimal neurologic impairment — no. of } \\
\text { patients }(\%)\end{array}$ & $1815(14.4)$ & $406(10.6)$ & $566(12.9)$ & $843(19.2)$ & $<0.001$ \\
\hline \multicolumn{6}{|l|}{ First shock with the use of a public-access AED } \\
\hline No. of patients receiving shock & 462 & 45 & 143 & 274 & \\
\hline Patient's age $-\mathrm{yr}$ & $62.1 \pm 16.5$ & $66.6 \pm 13.2$ & $63.6 \pm 15.4$ & $60.6 \pm 17.4$ & $<0.001$ \\
\hline Male sex - no. of patients (\%) & $361(78.1)$ & $34(75.6)$ & $108(75.5)$ & $219(79.9)$ & 0.31 \\
\hline Relationship of bystander to patient — no. (\%) & & & & & 0.01 \\
\hline Family member & $61(13.2)$ & $8(17.8)$ & $27(18.9)$ & $26(9.5)$ & \\
\hline Other & $401(86.8)$ & $37(82.2)$ & $116(81.1)$ & $248(90.5)$ & \\
\hline Time from collapse to first shock or initiation of CPR - min & $3.2 \pm 4.4$ & $3.6 \pm 5.1$ & $3.5 \pm 5.1$ & $2.9 \pm 3.8$ & 0.03 \\
\hline $\begin{array}{l}\text { Restoration of spontaneous circulation before arrival at hospital } \\
\qquad \text { no. of patients (\%) }\end{array}$ & $185(40.0)$ & $12(26.7)$ & $47(32.9)$ & $126(46.0)$ & 0.002 \\
\hline Survival at 1 mo - no. of patients (\%) & $172(37.2)$ & $11(24.4)$ & $47(32.9)$ & $114(41.6)$ & 0.01 \\
\hline $\begin{array}{l}\text { Survival at } 1 \text { mo with minimal neurologic impairment — no. of } \\
\text { patients (\%) }\end{array}$ & $146(31.6)$ & $11(24.4)$ & $41(28.7)$ & $94(34.3)$ & 0.11 \\
\hline
\end{tabular}

* Plus-minus values are means \pm SD. CPR denotes cardiopulmonary resuscitation.

$\uparrow$ Data on CPR initiated by bystander were missing for 63 events (19 in 2005, 27 in 2006, and 17 in 2007). Percentages were calculated on the basis of the total number of events, including those with missing data.

+ Conventional CPR included chest compressions and rescue breathing.

$\int$ Only patients who received a shock were considered in the calculation of time from collapse to first shock.

q Data on survival at 1 month with minimal neurologic impairment were missing for 55 patients (29 in 2005, 21 in 2006, and 5 in 2007). Percentages were calculated on the basis of the total number of patients, including those with missing data. 


\begin{tabular}{|c|c|c|}
\hline Factor & $\begin{array}{l}\text { Adjusted Odds } \\
\text { Ratio for Survival } \\
(95 \% \mathrm{Cl})\end{array}$ & $P$ Value \\
\hline Male sex & $0.90(0.79-1.04)$ & 0.15 \\
\hline Age $\geq 75 \mathrm{yr}$ & $0.41(0.35-0.48)$ & $<0.001$ \\
\hline \multicolumn{3}{|l|}{ Relationship of bystander to patient } \\
\hline Family member & Reference & \\
\hline Other & $1.32(1.10-1.59)$ & 0.002 \\
\hline \multicolumn{3}{|l|}{ Type of bystander-initiated CPR } \\
\hline No CPR & Reference & \\
\hline Chest compression only & $1.65(1.40-1.96)$ & $<0.001$ \\
\hline Conventional $\mathrm{CPR} \dagger$ & $1.67(1.40-2.00)$ & $<0.001$ \\
\hline $\begin{array}{l}\text { Time from collapse to initiation of CPR } \\
\text { (per l-minute increase) }\end{array}$ & $0.98(0.96-0.99)$ & 0.02 \\
\hline Use of AED & $1.21(0.81-1.82)$ & 0.35 \\
\hline $\begin{array}{l}\text { Interaction between provider of AED shock } \\
\text { and time to first shock }\end{array}$ & $1.02(0.96-1.09)$ & 0.50 \\
\hline $\begin{array}{l}\text { Time from collapse to first shock (per } \\
\text { 1-minute increase) }\end{array}$ & $0.91(0.89-0.92)$ & $<0.001$ \\
\hline
\end{tabular}

* AED denotes automated external defibrillator, $\mathrm{Cl}$ confidence interval, and CPR cardiopulmonary resuscitation.

$\uparrow$ Conventional CPR included chest compressions and rescue breathing.

ministration of the first shock did not change significantly $(\mathrm{P}=0.36)$. Consequently, the percentage of persons who survived and had minimal neurologic impairment at 1 month increased from $10.6 \%$ in 2005 (406 of 3841 persons) to $19.2 \%$ in 2007 (843 of 4402) $(\mathrm{P}<0.001)$. The percentage of patients who received a shock from a publicaccess AED increased from 1.2\% in 2005 (45 of 3841 patients) to $6.2 \%$ in 2007 (274 of 4402) $(\mathrm{P}<0.001$ for trend). The mean age of these patients decreased over the course of the 3-year study period from 66.6 years to 60.6 years $(\mathrm{P}<0.001)$, and the mean time from collapse to the administration of the first shock or initiation of CPR decreased from 3.6 minutes to 2.9 minutes $(\mathrm{P}=0.03)$. The proportion of arrests witnessed by family members was only $13.2 \%$. The frequency of a good neurologic outcome among patients who received a shock from a public-access AED increased from $24.4 \%$ in 2005 (11 of 45 patients) to $34.3 \%$ in 2007 (94 of 274), although the difference was not significant $(\mathrm{P}=0.11)$. Among patients who had a good neurologic outcome after ventric- ular fibrillation, the proportion who had received AED shocks administered by a bystander increased markedly, from $2.7 \%$ (11 of 406 patients) to $11.2 \%$ ( 94 of 843 patients) ( $\mathrm{P}<0.001$ for trend).

\section{FACTORS ASSOCIATED WITH A GOOD NEUROLOGIC OUTCOME}

In a multivariate analysis (Table 3), earlier administration of shock and earlier initiation of CPR were associated with a good neurologic outcome, but the provider of the shock (bystander or EMS personnel) was not (adjusted odds ratio per 1-minute increase in the time to administration of shock, $0.91 ; 95 \%$ confidence interval [CI], 0.89 to 0.92; adjusted odds ratio per 1-minute increase in the time to initiation of CPR, 0.98; 95\% CI, 0.96 to 0.99 ; adjusted odds ratio for shock administered by a bystander with the use of an AED, 1.21; $95 \%$ CI, 0.81 to 1.82). Both compression-only CPR and conventional CPR administered by a bystander were associated with a good neurologic outcome (adjusted odds ratio for compression-only CPR, 1.65; 95\% CI, 1.40 to 1.96; adjusted odds ratio for conventional CPR, 1.67; 95\% CI, 1.40 to 2.00 ).

\section{FACTORS ASSOCIATED WITH AVAILABILITY OF PUBLIC-ACCESS AEDS}

Table 4 shows the interval from a patient's collapse to the first administration of a shock from a public-access AED, the annual incidence of shocks administered with the use of a publicaccess AED, and the rate of survival with minimal neurologic impairment after the administration of shocks from a public-access AED, according to the number of public-access AEDs per square kilometer of inhabited area. The mean $( \pm S D)$ interval from a patient's collapse to defibrillation decreased as the number of public-access AEDs per inhabited area increased $(3.7 \pm 4.8$ minutes when there was $<1$ public-access AED per square kilometer, $3.2 \pm 5.3$ minutes when there were 1 to less than 4 , and 2.2 \pm 3.7 minutes when there were 4 or more; $\mathrm{P}<0.001)$. The annual number of patients per 10 million population who had minimal neurologic impairment after a shock from a public-access AED increased as the number of public-access AEDs per square kilometer of inhabited area increased $(2.4 \pm 4.1$ patients per 10 million population when there was $<1$ publicaccess AED per square kilometer, 7.6 \pm 5.1 when there were 1 to less than 4 , and $8.9 \pm 5.8$ when there were 4 or more) $(\mathrm{P}=0.01)$. 


\begin{tabular}{|c|c|c|c|c|}
\hline \multirow{3}{*}{$\begin{array}{l}\text { Variable } \\
\text { Prefectures (no.) † }\end{array}$} & \multicolumn{3}{|c|}{$\begin{array}{l}\text { No. of Public-Access AEDs } / \mathrm{km}^{2} \\
\text { of Inhabited Area }\end{array}$} & \multirow[t]{2}{*}{$\begin{array}{l}\text { P Value for } \\
\text { Trend }\end{array}$} \\
\hline & \multirow[t]{2}{*}{$<1$} & \multirow[t]{2}{*}{1 to $<4$} & \multirow[t]{2}{*}{$\geq 4$} & \\
\hline & & & & \\
\hline 2005 & 46 & 1 & 0 & \\
\hline 2006 & 43 & 3 & 1 & \\
\hline 2007 & 37 & 8 & 2 & \\
\hline Time from collapse to shock (min) & $3.7 \pm 4.8$ & $3.2 \pm 5.3$ & $2.2 \pm 3.7$ & $<0.001$ \\
\hline $\begin{array}{l}\text { Annual incidence of shock with } A E D \text {, per } 10 \text { million daytime } \\
\text { population }\end{array}$ & $7.7 \pm 8.1$ & $19.2 \pm 11.2$ & $29.6 \pm 14.8$ & $<0.001$ \\
\hline $\begin{array}{l}\text { Annual incidence of good neurologic outcome after shock } \\
\text { with AED, per } 10 \text { million daytime population }\end{array}$ & $2.4 \pm 4.1$ & $7.6 \pm 5.1$ & $8.9 \pm 5.8$ & 0.01 \\
\hline
\end{tabular}

\section{DISCUSSION}

An analysis of data from a nationwide registry of patients with out-of-hospital cardiac arrests showed that the number of patients who received shocks from public-access AEDs and who survived increased as the number of public-access AEDs increased year by year. Thus, our study shows the actual effect of the greater dissemination of public-access AEDs throughout Japan.

Our study shows that the reduction in time to the administration of a first shock that resulted from the nationwide dissemination of publicaccess AEDs increased the rate of survival after an out-of-hospital cardiac arrest. Previous studies have shown mixed results of public-accessdefibrillation programs, but all these studies were conducted in limited areas or situations. ${ }^{1,5-12}$ Even the Public Access Defibrillation trial (PAD; ClinicalTrials.gov number, NCT00004560), which was a large, community-based intervention trial involving 19,000 volunteers, ${ }^{5}$ did not show whether the nationwide dissemination of public-access AEDs would actually increase the rate of survival after cardiac arrests, because an intervention trial itself is a special situation. Our study, which shows the success of nationwide dissemination of public-access AEDs, provides support for the concept of public-access defibrillation and should encourage other countries or communities to promote public-access-defibrillation programs.

We also found that increasing the number of public-access AEDs per square kilometer of inhabited area was strongly associated with shortening the time to the administration of a first shock and in increasing the number of patients who survived with minimal neurologic impairment after receiving a shock. On the basis of our data, we can extrapolate that if the number of public-access AEDs increased from 1 per square kilometer (i.e., a unit placed every 1000 linear meters) to more than 4 per square kilometer (i.e., a unit placed every 500 linear meters), the rate of survival with minimal neurologic impairment in the area could increase about four times. These data support the recommendation that public-access AEDs be made available within a 1.0-minute to 1.5 -minute brisk walk from any location..$^{23}$ Although the number of public-access AEDs per square kilometer of inhabited area increased during the 3 years of the study, their availability is still not sufficient in most areas.

In Japan, the placement of public-access AEDs is not controlled and depends on both public and private initiatives. ${ }^{20} \mathrm{~A}$ total of $25 \%$ of publicaccess AEDs are located in schools, $19 \%$ in medical or nursing facilities, $16 \%$ in workplaces, $4 \%$ in sports facilities, $3 \%$ in cultural facilities, and $3 \%$ in public transportation facilities. ${ }^{21}$ Depending on the location, AEDs have been shown to be either very effective in reducing mortality after out-of-hospital arrests among patients with ventricular fibrillation (e.g., in airports or casinos) $)^{5-9}$ or of minimal effectiveness (e.g., in homes). ${ }^{12}$ The 
association between the locations of public-access AEDs and their effectiveness requires further investigation.

In this study, we observed a significant improvement in the rate of survival in the brief span of 3 years. There may be various factors other than the dissemination of public-access AEDs that would improve the outcome of out-ofhospital cardiac arrest. The improvement in survival that occurred during the study period could be explained in part by the changes to the 2005 CPR guidelines. ${ }^{24}$ Advanced life-support treatments administered before arrival at the hospital, as well as special treatments administered in the hospital, such as hypothermia, might result in improved survival after an out-of-hospital cardiac arrest. ${ }^{25,26}$ However, the notable increase in the proportion of patients who received AED shocks administered by bystanders among patients who had a good neurologic outcome after ventricular fibrillation suggests the effect of the dissemination of public-access AEDs on improving survival.

This study underscores the importance not only of shocks administered early after a cardiac arrest but also of bystander-initiated CPR, irrespective of the type of CPR. The time from a patient's collapse to the initiation of CPR was reduced because of the increase in bystanderinitiated CPR, and both early shock and early initiation of CPR contributed to a better outcome. Familiarity with the use of an AED, along with increased dissemination of public-access AEDs, might promote both a willingness to use an AED and a positive attitude toward CPR. ${ }^{27}$ A previous study showed that dissemination of public-access AEDs without an emphasis on CPR did not improve the rate of survival after an out-of-hospital cardiac arrest. ${ }^{28}$ The present study reinforces the importance of the combination of early initiation of CPR and early defibrillation. ${ }^{1}$

Although public-access AEDs are becoming increasingly available, among patients with outof-hospital cardiac arrests who have ventricular fibrillation, the frequencies of shock administration and CPR initiation by bystanders are still only $7 \%$ and $50 \%$, respectively, and the rate of survival is still low. Even in the intensive intervention trial of public-access defibrillation, CPR was attempted by a bystander in only half the cases of out-of-hospital cardiac arrests that were witnessed by bystanders, and a public-access AED was used in only one third of the cases. ${ }^{5}$ Using an AED and performing CPR are known to be difficult for laypersons. ${ }^{23}$ To overcome this problem, the use of CPR that involves chest compression only, a skill that is simpler and easier to learn and perform, should be encouraged. ${ }^{29,30}$ Further efforts are warranted to strengthen the four elements in public-access-defibrillation programs - planning the program, training laypersons, establishing a link with the EMS system, and setting up a system for maintaining the device and for monitoring quality improvement. ${ }^{23}$

This study has some limitations. First, we did not obtain detailed information on the place of collapse or on the location of the public-access AED. Second, we had data only on cases in which public-access AEDs were used and the shock was delivered; we did not have data on cases in which an attempt was made to use an AED but the shock was not delivered. Therefore, we could not evaluate how many cases there were in which an attempt was made to use an AED in patients who did not have ventricular fibrillation or how many cases there were in which a patient with ventricular fibrillation did not receive a shock because of human or mechanical error. Since AEDs have a high sensitivity for detecting ventricular fibrillation, however, one can assume that they would rarely miss ventricular fibrillation. ${ }^{31}$ Third, information is lacking on the bystanders who used AEDs, including the conditions under which they witnessed the out-of-hospital cardiac arrest and administered shocks. Fourth, as with all epidemiologic studies, the integrity and validity of the data, as well as ascertainment bias, are potential limitations of our study. The use of uniform data collection based on Utstein-style guidelines for reporting cardiac arrest, the large sample size, and the population-based design should minimize these potential sources of bias. If the rate of survival is improved by the dissemination of public-access AEDs, it is also essential to perform an economic analysis. Investigators in the PAD trial estimated that the cost-effectiveness of publicaccess defibrillation was similar to that of other medical interventions. ${ }^{32}$

In conclusion, this large, population-based, observational study showed that nationwide dissemination of public-access AEDs increased the frequency of the administration of shocks with 
the use of public-access AEDs and contributed to improved outcomes after out-of-hospital ventricular-fibrillation arrests of cardiac origin that were witnessed by bystanders. This finding reinforces the importance of the public-access-defibrillation concept for increasing survival after out-ofhospital cardiac arrests.

Supported by grants from the Fire and Disaster Management Agency (to Dr. Hiraide, on behalf of the study group concerning strategy for applying the results of Utstein report for improvement of emergency service) and the Ministry of Education, Culture, Sports, Science and Technology (19390458).

No potential conflict of interest relevant to this article was reported.

We thank all the emergency medical services personnel and concerned physicians in Japan, and the staffs of the Fire and Disaster Management Agency and Institute for Fire Safety and Disaster Preparedness of Japan for their generous cooperation in establishing and following the Utstein database; and Seishiro Marukawa for providing the essential data on the number of public-access automated external defibrillators in Japan.

\section{APPENDIX}

The investigators and coordinators participating in the Implementation Working Group for the All-Japan Utstein Registry of FDMA are as follows. Writing Committee: T. Kitamura, T. Iwami, T. Kawamura, K. Nagao, H. Tanaka, A. Hiraide. Investigators and coordinators (all in Japan): Disaster Prevention Bureau, Aichi Prefectural Government Office, Aichi: T. Iwasa. Ambulance Service Planning Office, Fire and Disaster Management Agency, Tokyo: T. Mizoguchi, T. Kaito, T. Koitabashi, H. Kaide. Foundation for Ambulance Service Development, Tokyo: N. Asahi. Institute for Fire Safety and Disaster Preparedness, Tokyo: Z. Hu. Kokushikan University, Tokyo: H. Tanaka. Kyoto University, Kyoto: T. Kitamura, T. Iwami, T. Kawamura, A. Hiraide. National Cardiovascular Center, Suita: T. Okamura. Nippon Medical School, Tokyo: H. Yokota. Osaka Municipal Fire Department, Osaka: S. Nisou. Saga Fire Bureau, Saga: K. Ogata. Sapporo Fire Bureau, Sapporo: Y. Sasaki. Surugadai Nihon University Hospital, Tokyo: K. Nagao. Teikyo University, Tokyo: T. Sakamoto. Tokyo Rinkai Hospital, Tokyo: Y. Yamamoto. Yokohama City Safety Management Bureau, Yokohama: K. Kikuchi.

\section{REFERENCES}

1. 2005 American Heart Association guidelines for cardiopulmonary resuscitation and emergency cardiovascular care. Circulation 2005;112:Suppl:IV-1-IV-203.

2. Iwami T, Nichol G, Hiraide A, et al. Continuous improvements in "chain of survival" increased survival after out-ofhospital cardiac arrests: a large-scale population-based study. Circulation 2009;119: 728-34.

3. Rea TD, Eisenberg MS, Becker LJ, Murray JA, Hearne T. Temporal trends in sudden cardiac arrest: a 25-year emergency medical services perspective. Circulation 2003;107:2780-5.

4. Larsen MP, Eisenberg MS, Cummins RO, Hallstrom AP. Predicting survival from out-of-hospital cardiac arrest: a graphic model. Ann Emerg Med 1993;22:1652-8.

5. The Public Access Defibrillation Trial Investigators. Public-access defibrillation and survival after out-of-hospital cardiac arrest. N Engl J Med 2004;351:637-46.

6. Valenzuela TD, Roe TD, Nichol G, Clark LL, Spaite DW, Hardman RG. Outcomes of rapid defibrillation by security officers after cardiac arrest in casinos. N Engl J Med 2000;343:1206-9.

7. Page RL, Joglar JA, Kowal RC, et al. Use of automated external defibrillators by a U.S. airline. N Engl J Med 2000;343: 1210-6.

8. Caffrey SL, Willoughby PJ, Pepe PE, Becker LB. Public use of automated external defibrillators. N Engl J Med 2002; 347:1242-7.

9. Capucci A, Aschieri D, Piepoli MF, Bardy GH, Iconomu E, Arvedi M. Tripling survival from sudden cardiac arrest via early defibrillation without traditional education in cardiopulmonary resuscitation. Circulation 2002;106:1065-70.
10. White RD, Bunch TJ, Hankins DG. Evolution of a community-wide early defibrillation program experience over 13 years using police/fire personnel and paramedics as responders. Resuscitation 2005;65: 279-83.

11. van Alem AP, Vrenken RH, de Vos R, Tijssen JG, Koster RW. Use of automated external defibrillator by first responders in out-of-hospital cardiac arrest: prospective controlled trial. BMJ 2003;327:1312-7. 12. Bardy GH, Lee KL, Mark DB, et al. Home use of automated external defibrillators for sudden cardiac arrest. $\mathrm{N}$ Engl J Med 2008;358:1793-804.

13. Report on a study on social system development to improve survival from emergency cardiovascular disease using automated external defibrillator (Marukawa's report). (In Japanese.) (Accessed June 20, 2009, at http://kouroukaken-kyukyusosei .info/wpm/archivepdf/19/2_3b.pdf.)

14. Cummins RO, Chamberlain DA, Abramson NS, et al. Recommended guideline for uniform reporting of data from out-of-hospital cardiac arrest: the Utstein style - a statement for health professionals from a task force of the American Heart Association, the European Resuscitation Council, the Heart and Stroke Foundation of Canada, and the Australian Resuscitation Council. Circulation 1991;84: 960-75.

15. Jacobs I, Nadkarni V, Bahr J, et al. Cardiac arrest and cardiopulmonary resuscitation outcome reports: update and simplification of the Utstein templates for resuscitation registries: a statement for healthcare professionals from a task force of the International Liaison Committee on Resuscitation. Circulation 2004;110:338597.
16. Social indicators by prefecture 2005 . Tokyo: Japan Statistical Association, 2005. 17. 2005 Population census of Japan. Tokyo: Japan Statistical Association, 2006.

18. Japanese guidelines for emergency care and cardiopulmonary resuscitation. 3rd ed. Tokyo: Health Shuppansha, 2007. 19. Ambulance Service Planning Office of Fire and Disaster Management Agency of Japan. Effect of first aid for cardiopulmonary arrest. Tokyo: Ministry of Internal Affairs and Communications. (In Japanese.) (Accessed January 25, 2010, at http:// www.fdma.go.jp/neuter/topics/houdou/ 2101/210122-1houdou.pdf.)

20. Mitamura H. Public access defibrillation: advances from Japan. Nat Clin Pract Cardiovasc Med 2008;5:690-2.

21. Japan foundation for emergency medicine: a search for information about placement of AEDs. (In Japanese.) (Accessed January 25, 2010, at http://www.qqzaidan .jp/AED/aed.htm.)

22. Vital statistics of Japan 2005. Tokyo: Health and Welfare Statistics Association, 2007.

23. Hazinski MF, Idris AH, Kerber RE, et al. Lay rescuer automated external defibrillator ("public access defibrillation") programs: lessons learned from an international multicenter trial: advisory statement from the American Heart Association Emergency Cardiovascular Care Committee; the Council on Cardiopulmonary, Perioperative and Critical Care; and the Council on Clinical Cardiology. Circulation 2005;111:3336-40.

24. Rea TD, Helbock M, Perry S, et al. Increasing use of cardiopulmonary resuscitation during out-of-hospital cardiac arrest: survival implications of guideline changes. Circulation 2006;114:2760-5. 
25. The Hypothermia after Cardiac Arrest Study Group. Mild therapeutic hypothermia to improve the neurological outcomes after cardiac arrest. N Engl J Med 2002; 346:549-56.

26. Bernard SA, Gray TW, Buist MD, et al. Treatment of comatose survivors of outof-hospital cardiac arrest with induced hypothermia. N Engl J Med 2002;346:557-63. 27. Kuramoto N, Morimoto T, Kubota Y, et al. Public perception of and willingness to perform bystander CPR in Japan. Resuscitation 2008;79:475-81.

28. Cobb LA, Fahrenbruch CE, Walsh TR, et al. Influence of cardiopulmonary resuscitation prior to defibrillation in patients with out-of-hospital ventricular fibrillation. JAMA 1999;281:1182-8.

29. Sayre MR, Berg RA, Cave DM, Page RL, Potts J, White RD. Hands-only (compression-only) cardiopulmonary resuscitation: a call to action for bystander response to adults who experience out-of-hospital sudden cardiac arrest: a science advisory for the public from the American Heart Association Emergency Cardiovascular Care Committee. Circulation 2008;117:2162-7.

30. Nishiyama C, Iwami $T$, Kawamura $T$, et al. Effectiveness of simplified chest compression-only CPR training for the general public: a randomized controlled trial. Resuscitation 2008;79:90-6.

31. Macdonald RD, Swanson JM, Mottley JL, Weinstein C. Performance and error analysis of automated external defibrillator use in the out-of-hospital setting. Ann Emerg Med 2001;38:262-7.

32. Nichol G, Huszti E, Birnbaum A, et al. Cost-effectiveness of lay responder defibrillation for out-of-hospital cardiac arrest. Ann Emerg Med 2009;54:226-35.

Copyright (c) 2010 Massachusetts Medical Society. 